\title{
A comunicação da dor: um estudo sobre as narrativas dos impactos da disfunção temporomandibular ${ }^{*}$
}

Luciana Studart ${ }^{1}$

Moab Duarte Acioli

STUDART, L.; ACIOLI, M.D. Pain communication: a study of narratives about the impacts of the temporomandibular disorder. Interface - Comunic., Saude, Educ., v.15, n.37, p.487-503, abr./jun. 2011.

In the field of health there has been an increasing interest in carrying out research relating pain to quality of life. However, many studies of this nature are primarily quantitative analyses. Accordingly, there is a need to develop methods of study that focus on the perspective of the individual and promote a better understanding of the experience of suffering. This paper set out to study the narratives of individuals with Temporomandibular Disorder related to the impact of pain on social, leisure and family activities. It was a qualitative and exploratory study. Semi-structured interviews were conducted, recorded, and subsequently transcribed to constitute the corpus of this project. The discussion of the results was based on content analysis. The results showed that overall impacts of the pain caused by Temporomandibular Disorder on the individual's life concern predominantly leisure and work. Specific impacts include chewing, yawning, practising oral hygiene, smiling and speaking.

Keywords: Communication. Orofacial pain. Narratives. Quality of life.
O interesse em pesquisas que relacionam dor e qualidade de vida tem sido frequente no campo da saúde. No entanto, grande parte desses estudos destina-se a análises quantitativas. Nesse sentido, há uma demanda em se desenvolver métodos de estudos, por meio de instrumentos que considerem a perspectiva do sujeito e que permitam uma melhor compreensão da experiência de sofrimento. O presente artigo refere-se a um estudo exploratório, qualitativo, sobre as narrativas de sujeitos com Disfunção Temporomandibular relacionadas aos impactos da dor nas atividades sociais, de lazer e familiares. Para a constituição do corpus foram realizadas entrevistas semiestruturadas, gravadas e transcritas. A discussão dos resultados baseou-se na Análise de Conteúdo. Os resultados indicaram que os impactos gerais da dor da Disfunção Temporomandibular na vida do sujeito são predominantemente no lazer e no trabalho. Entre os impactos específicos, mastigar, bocejar, fazer higiene oral, sorrir e falar.

Palavras-chave: Comunicação. Dor orofacial. Narrativas. Qualidade de vida.

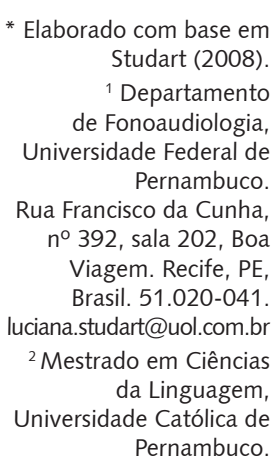
Pernambuco. Pernambuco. 


\section{Introdução}

A disfunção temporomandibular (DTM) caracteriza-se por uma heterogeneidade de sintomas clínicos envolvendo alterações relacionadas com a musculatura da mastigação, a articulação temporomandibular (ATM) ou ambas as estruturas (Kosminsky et al., 2004). Entre os sintomas, destacam-se: cefaleia, dor na região articular e na musculatura mastigatória e cervical. E, entre os sinais, observa-se limitação dos movimentos mandibulares (Siqueira, Teixeira, 2001).

O estudo procura captar, por meio das narrativas, aspectos subjetivos relacionados à experiência de ser portador de DTM, aspectos esses que têm sido objeto de estudo das ciências sociais e humanas aplicadas à saúde. Nesse sentido, este trabalho implica uma tentativa de ampliação do conceito teórico da dor, articulando o saber científico-formal com aquele subjetivo-leigo. Num sentido de intervenção clínica, pode propiciar um novo modo de comunicação entre o profissional e o paciente ${ }^{3}$, destacando a importância desta, tanto quanto das ações instrumentais.

A DTM pode promover um importante impacto para o sujeito, comprometendo a capacidade funcional das funções orais (Zarb et al., 2000). Mas, além do caráter orgânico, é também acompanhada de fatores psicossociais próprios dos distúrbios dolorosos. Nesse sentido, a relação profissional-paciente pode ser fundamental para o sucesso do tratamento (Garcia et al., 2000).

O objetivo deste trabalho foi estudar os enunciados dos sujeitos portadores de DTM sobre a experiência dessa dor orofacial na suas vidas, e apreender o impacto da experiência de ser portador de DTM nas atividades sociais, de lazer e familiares.

\section{Impactos da dor na qualidade de vida}

O impacto negativo da disfunção temporomandibular na vida dos seus portadores está associado ao grau de severidade de muitos fatores psicossociais e psicológicos (Lucena, 2004). Assim, devido à importância da cavidade bucal - em termos de ser básica para a alimentação, de expressar as emoções e de se comunicar -, as manifestações da DTM e outras condições de dor orofacial fundamentam a hipótese de que essa doença tem um impacto significativo na qualidade de vida (Murray et al., 1996).

Trata-se de uma dor que impede os sujeitos de executarem muitas ações do dia a dia, e de participarem de algumas interações sociais, podendo resultar em afastamento integral de muitas atividades, comprometendo a autoestima e tornando a vida controlada por essa experiência (Grzesiak, 1991).

Oliveira et al. (2003) também destacam que, além dos componentes físicos e químicos envolvidos no evento doloroso da DTM, devem ser considerados os aspectos subjetivos e psicológicos, pois são cruciais na compreensão da queixa dolorosa.

Instrumentos como o Oral Impacts on Daily Performance (OIDP), também estudados por Lucena (2004), destacam o impacto da dor orofacial em nove atividades da vida diária, como: o desempenho ao comer, falar, limpar a boca ou a face; dormir; a aparência; o estado emocional; a realização de tarefas usuais, e a prática de atividades de lazer e de esporte. Essas atividades foram estudadas numa perspectiva clínico-quantitativa. Sendo a mesma fundamentada em instrumentos com categorias a priori, foi relevante desenvolver um estudo que possa registrar aspectos semânticos e lógicos a posteriori presentes na produção dos enunciados desses sujeitos.

\author{
${ }^{3}$ O termo "paciente" \\ será utilizado neste \\ trabalho quando se \\ referir às relações \\ clínicas com médicos ou \\ outros profissionais de \\ saúde, ou em respeito \\ à terminologia utilizada \\ pelos autores aqui \\ citados.
}


${ }^{4}$ Histórico que vai desde os sintomas iniciais até o momento da observação clínica, realizado com base nas lembranças do paciente (Dicionário, 2008).

${ }^{5}$ Qualquer fragmento conexo de escrita ou fala (Trask, 2004).
Embora seja pequeno o número de estudos que documenta o impacto da DTM na qualidade de vida, utilizando questionários específicos ou ferramentas multidimensionais, outro trabalho que se destaca é o de Oliveira et al. (2003). Esse estudo teve o objetivo de descrever os relatos subjetivos de portadores de DTM sobre o impacto da dor em suas vidas.

Tendo em vista a necessidade de se desenvolverem métodos de estudo e de avaliação, por meio de instrumentos que considerem a perspectiva leiga, e não apenas a dos cientistas e profissionais de saúde (Slevin et al., 1988), foi intenção deste estudo abordar a relação entre dor e qualidade de vida a partir da perspectiva do sujeito que vive a experiência.

\section{Narrativas no campo da saúde}

O campo da saúde utiliza, como narrativa, o relato dos sujeitos sobre a história de suas doenças, em especial, no momento da anamnese ${ }^{4}$.

Nesse sentido, as narrativas podem ser definidas como tipo de discurso ${ }^{5}$ onde são contados acontecimentos numa estrutura sequencial, cuja forma mais elementar apresenta uma introdução, um desenvolvimento e uma conclusão. Costuma-se caracterizá-la como a descrição de um passado recente ou remoto, seja ele mítico ou histórico, ficcional ou realista, pessoal ou coletivo, entre outros (Langdon,1994).

Autores como Silva e Trentini (2002) discutem que, na análise das narrativas, são buscados os usos da linguagem, não visando apenas à informação, mas a realização de vários tipos de ação, entre eles: o diálogo e a argumentação.

Os autores, com base nos levantamentos da literatura e da sua experiência com o uso desse recurso no campo da enfermagem, classificam as narrativas em três grupos:

a) Narrativas breves: são narrativas sintéticas, contendo estrutura mínima de uma narrativa (começo, meio e fim), em que é facilmente identificada a sequência do enredo e onde é focalizado um determinado episódio, como a descoberta da doença, um súbito mal-estar;

b) Narrativas de vivência: são mais amplas, incluindo a história da vivência de uma pessoa com a doença e vários episódios que, geralmente, são colocados numa sequência de acontecimentos, dos quais nem sempre há uma interpretação temporal, construindo-se a experiência como processo;

c) Narrativas populares: são as histórias contadas e recontadas entre pessoas de uma comunidade, podendo tornar-se lendas.

Vale ressaltar a importância dos relatos da descrição da dor e do impacto na qualidade de vida de seus portadores, pois se acredita que apenas por meio do entendimento da experiência é possível acessar o caráter singular do sofrimento e direcionar o diagnóstico e a terapêutica, levando em conta as peculiaridades de cada sujeito.

Lima e Rivera (2009, p.335), em uma abordagem teórico-metodológica para estudos na área da integração de serviços de saúde, destacam que a ação comunicativa é essencial para os processos de interação e de compreensão da realidade do outro. Sobre isso é dito:

Quando um sujeito fala, não apenas descreve a realidade pura e simplesmente; ele gera realidade. A concepção de linguagem como ação supera a visão de que ela seria algo passivo, descritivo, onde a realidade viria primeiro e a linguagem serviria para descrevê-la. 
Tomar as entrevistas como técnicas de coleta de dados, objetivando o acesso à experiência da doença, não significa estabelecer uma equivalência ou uma redução da experiência ao discurso narrativo (Alves, Rabelo, 1999), mas constatar que existe uma vinculação estreita entre a experiência do sujeito e o que é dito por ele.

Para Lira, Catrib e Nations (2003), a narrativa pode ser usada no âmbito de uma estratégia de métodos combinados, onde ela provê, a partir de uma abordagem a um pequeno grupo de sujeitos, um atendimento em maior profundidade da realidade estudada, permitindo uma avaliação abrangente dos mesmos, tais como vivenciados no contexto da vida real.

Através da narrativa, destacam Jovchelovitch e Bauer (2002), as pessoas lembram o que aconteceu, colocam a experiência em uma sequência, encontram possíveis explicações para isso, e jogam com a cadeia de acontecimentos que constroem a vida individual e social. Contar histórias implica estados intencionais que aliviam ou, ao menos, tornam familiares, acontecimentos e sentimentos que confrontam a vida cotidiana normal.

Sendo, pois, esse processo de falar sobre a experiência uma atividade reflexiva que nos ajuda a conhecer os significados de determinados eventos localizados no tempo pretérito, essa possibilidade evidentemente também nos ajuda a compreender as situações atuais (Turner, 1984). Nesse aspecto, junto a essa possibilidade de compreensão transtemporal, tanto no passado quanto no presente, destaca-se uma outra transcultural, pois elas são "metacódigos" que permitem uma tradução de outras realidades culturais e pessoais, facilitando um entendimento daquilo que se caracteriza como diferença (White, 1981).

Silva e Trentini (2002, p.431) também escrevem que contar

\begin{abstract}
histórias sobre a doença, portanto, é uma forma de tornar a experiência passada disponível para outros, que as recontarão, criando, então, uma rede de informações que permitirá sempre um novo contar sobre sua própria experiência a partir de outras experiências. [...] Ao serem registradas, essas histórias tornam-se disponíveis a 'leitores' múltiplos, abrindo, portanto, novas possibilidades de interpretações.
\end{abstract}

Essa compreensão é subjetiva, e, por consequência de sua dor, requer uma abordagem mais ampla que aquela que só se preocupa com dados da patologia. Entretanto, e infelizmente, para o modelo biomédico predominante da sociedade moderna, saúde e doença constituem fenômenos de ordem biológica, que devem ser tratados por meio de uma ação de natureza prioritariamente técnica.

As premissas básicas da perspectiva biomédica incluem: a racionalidade científica; a ênfase na mensuração objetiva e numérica de dados bioquímicos; o mecanicismo; o dualismo corpo-mente; a visão da enfermidade como entidade ontológica (atribuindo-lhe uma identidade mórbida que é independente do sujeito e do contexto sociocultural em que está inserido) e a ênfase do diagnóstico e tratamento sobre o indivíduo doente em detrimento da família ou da comunidade (Helman, 2003).

Essas premissas, de acordo com Iriart (2003, p.5),

refletem-se de várias formas na prática médica, por exemplo, no momento em que a desordem orgânica é percebida como verdadeiro objeto da medicina; quando a racionalidade científica despreza as dimensões emocionais e morais da aflição; quando o médico se coloca na posição de conhecedor ativo, deixando o paciente na condição de conhecedor passivo; e na despersonificação dos pacientes. Em especial a dificuldade dos médicos na escuta das queixas dos pacientes repercute de forma negativa na qualidade da relação terapêutica.

Na tentativa de compreender as dimensões objetivas e subjetivas da doença e valorizar a importância da experiência dos sujeitos, observam-se os conceitos da antropologia médica - disease e illness. 
${ }^{6}$ Medicina clínica baseada nos princípios das ciências naturais (biologia, bioquímica, biofísica etc) (Dicionário, 2008).
Disease, que pode ser relacionado à patologia, refere-se à doença tal como concebida pela biomedicina ${ }^{6}$, designando anormalidades na estrutura ou função dos órgãos ou sistemas orgânicos, e a estados patológicos, independentemente de serem ou não culturalmente reconhecidos (Kleinman, 1980).

O conceito illness está relacionado à percepção e à experiência do paciente da patologia, independentemente de serem reconhecidas, pela biomedicina, como doença. Esse conceito é especialmente importante para este estudo, pois remete aos significados que o sujeito atribui aos sinais e sintomas corporais, que podem ou não ser interpretados por ele e por seu meio cultural como doença.

Segundo Good (1994), as narrativas illness são histórias sobre a vida dos pacientes e sobre o modo como essa doença é vivida, a forma de representação, de expressão e de construção dessa experiência, sendo isso pautado por meio das interações sociais, nas trocas de comunicação e de outras experiências intersubjetivas e nas reelaborações dos conceitos e das práticas.

Trata-se, então, do modo como a doença é trazida à experiência individual e se torna significativa para o sujeito pois, para que a pessoa se reconheça como doente, é necessário que ela interprete os sintomas experienciados como sinais de uma doença. Essa maneira de interpretar, assim como a forma de expressar, é fortemente influenciada pelo contexto cultural em que o sujeito está inserido.

Segundo Kleinman (1980, p.120),

\begin{abstract}
Usos de modelos explicativos apontam para a base cognitiva das experiências de doença, revelando a respectiva análise das operações cognitivas no cerne da prática clínica. É esta estrutura cognitiva que demonstra mais claramente as relações entre pacientes e médicos, a doença e a cura, e o seu contexto cultural.
\end{abstract}

Grande parte da dificuldade encontrada nas relações terapêuticas deve-se ao fato de que o objeto terapêutico do modelo biomédico é a intervenção no processo da doença, visando a cura da patologia (disease), sem considerar a sua dimensão subjetiva (illness).

Nesse sentido, acredita-se que a análise do conteúdo de entrevistas de sujeitos, ao descreverem sua dor, permite uma adequada integração e compreensão da experiência subjetiva do adoecer, expressa por intermédio do modelo illness com determinados contextos de vida, familiares, sociais, históricos, entre outros. E mais, esses relatos parecem que, além de possibilitarem um melhor entendimento do que acontece na vida dos sujeitos, como afirma Boehs (2000), também permitem uma reordenação dessa vida na realidade da doença.

\section{Metodologia}

Este estudo foi de natureza qualitativa e exploratória (Minayo, 2006). Fundamentou-se no questionamento: Qual a contribuição do estudo das narrativas entre portadores de DTM para uma melhor compreensão da experiência de sofrimento?

Tratou-se de um estudo que envolveu empiricamente a comunicação dos sujeitos com a pesquisadora, tendo como base as tarefas de descrição, análise e interpretação das mensagens/enunciados dos mesmos sobre a experiência da dor e do impacto nas suas condições de singularidade. 
A pesquisa desenvolveu-se no Centro de Controle da Dor Orofacial (CCDO) da Faculdade de Odontologia de Pernambuco (FOP) - Universidade de Pernambuco (UPE), e correspondeu a uma das etapas de coleta de dados para uma dissertação de Mestrado, no período de junho a agosto de 2007.

Participaram 18 sujeitos, que foram selecionados com base em critérios clínicos e socioculturais, ou seja, por possuírem sintomatologia semelhante de dor orofacial e usuários do setor público de saúde.

Foram utilizados, como critérios de inclusão: possuir diagnóstico de portador de DTM, segundo índice anamnésico do Questionário Anamnésico Simplificado - DMF (Fonseca et al., 1994); apresentar respostas positivas referentes ao tempo de duração e frequência da dor; estar participando pela primeira vez de um estudo dessa natureza. Foram excluídos apenas os sujeitos que apresentassem discurso vago a ponto de comprometer a aplicação do roteiro da pesquisa.

Após a triagem inicial, os participantes responderam a uma entrevista semiestruturada, que constava de perguntas norteadoras elaboradas a partir de algumas perguntas baseadas no questionário Research Diagnostic Criteria for Temporomandibular Disorders: Axis II (RDC), já validado através de adaptação cultural (Kosminsky et al., 2004).

Do universo de enunciados coletados por meio de gravador digital Panasonic RR-US450 e transcritos pelo padrão de transcrição do projeto NURC - Norma Linguística Urbana Culta (Preti, 2000), foram selecionados os dados obtidos relacionados às questões referentes aos temas propostos.

A análise dos resultados se fundamentou na análise de conteúdo, segundo Bardin (1995, p.31).

Foram utilizadas unidades de análise, consideradas categorias teóricas e metodológicas, apontadas por Franco (2003) como estratégias na análise de conteúdo - a unidade de registro.

Nessa pesquisa, como unidade de registro, foi escolhido o tema, que pode ser uma frase, uma palavra ou um parágrafo. Apesar de apresentar algumas limitações, como a exigência de muito tempo para a coleta dos dados e a dificuldade de sua identificação, ele é considerado a mais útil unidade de registro em análise de conteúdo.

Ocorreram três níveis de construção da análise, conforme apresentado no Quadro 1.

$1{ }^{\circ}$ Nível: Com base no roteiro de entrevista semiestruturada foram elaborados eixos temáticos fundamentados a priori pelo pesquisador;

$2^{\circ}$ Nível: Os temas que surgiram na produção empírica a posteriori foram definidos como unidades temáticas (UT), devidamente conceituadas e classificadas;

$3^{\circ}$ Nível: As unidades temáticas foram quantificadas de modo absoluto como frequência de ocorrência (FO).

Com a necessidade da inclusão de alguns indicadores de frequência, que poderiam servir de referência para estudos posteriores, recorreu-se a uma análise quantitativa sistemática para que fosse possível identificar a frequência absoluta dos temas escolhidos e a proporcionalidade de sua menção em relação a outros temas igualmente presentes, como sugere Franco (2003).

A pesquisa foi aprovada pelo Comitê de Ética da Universidade Católica de Pernambuco.

Com o objetivo de garantir a privacidade dos participantes, seus nomes foram substituídos pela letra "E" (Entrevistado), seguidos de número de identificação.

\section{Resultados e discussão}

É muito relevante o impacto que a dor crônica na face pode causar na vida dos sujeitos, pois, geralmente, limita as atividades e interfere no convívio social e afetivo. Varia de limitações específicas, como dificuldade para sorrir, falar ou mastigar, a alterações globais na qualidade de vida. Essa dor, geralmente, ocasiona sérios comprometimentos às atividades do cotidiano, ao trabalho e ao convívio social. São características e impactos de natureza subjetiva que variam de pessoa para pessoa e, somente, por meio da comunicação, podem ser transmitidas ao profissional de saúde.

No estudo de Oliveira et al. (2003), sobre o impacto da dor na vida de portadores de DTM, observou-se que, nas perguntas específicas para avaliar o impacto da dor na vida dos portadores com quadro crônico, o trabalho, as atividades escolares, o sono e o apetite/alimentação foram as categorias mais influenciadas pelo quadro doloroso. 
Em se tratando dos impactos gerais, Siqueira (2004, p.42) destaca que:

No modelo biopsicossocial da dor, não se pode isolar o paciente da sua família ou de seus ambientes sociais de trabalho. A complexidade dessas associações exige atenção por parte dos profissionais da área de saúde ao abordarem seus pacientes crônicos. A dor, incluindo a dor orofacial, pode ser incapacitante e afastar temporariamente o indivíduo de seu local de trabalho. Por outro lado, o próprio trabalho pode ser fator agravante da condição dolorosa.

Trata-se da importância de conhecer o paciente um pouco além dos sintomas. A dor como causadora de impactos importantes provoca a necessidade de se entender como esses impactos repercutem para cada sujeito de forma particular.

O relato dos pacientes sobre suas doenças, os detalhes sobre os hábitos alimentares, atividades diárias, tipo de atividade profissional e demais informações, são fundamentais não só para o fechamento do diagnóstico, mas, especialmente, para a conduta terapêutica. Colaborando com essa ideia, Santos (1999, p.94), em seu trabalho "Ouvir o paciente: a anamnese no diagnóstico clínico", destaca que a anamnese é o elemento mais importante da clínica para o estabelecimento da relação médico/paciente, do diagnóstico e das condutas terapêuticas que irão determinar a cura ou alívio do paciente. Trata-se de um ato de comunicação, que exige do profissional de saúde: qualidade primordial de um bom ouvinte, uma interação e identificação recíproca com o seu paciente.

\section{Impactos gerais em ser portador de DTM}

O tópico "impactos gerais" foi subdividido nos seguintes eixos temáticos: "lazer", "limitações para o trabalho/estudo", e "realização das atividades domésticas".

Quadro 1. Impactos gerais em ser portador de DTM. Recife, 2010

\begin{tabular}{|l|c|c|c|}
\hline \multicolumn{1}{|c|}{ Eixos temáticos } & $\begin{array}{c}\text { Número de Unidades } \\
\text { Temáticas (UT) por } \\
\text { eixo temático }\end{array}$ & Unidades temáticas & $\begin{array}{c}\text { Frequência de } \\
\text { ocorrência (FO) por } \\
\text { unidade temática }\end{array}$ \\
\hline a. Lazer & 02UT & $\begin{array}{l}\text { Dificuldade em participar de } \\
\text { festas familiares, eventos e } \\
\text { passeios }\end{array}$ & $09 \mathrm{FO}$ \\
\cline { 3 - 4 } & \multirow{2}{*}{ 02UT } & $\begin{array}{l}\text { Limitação em participar de } \\
\text { atividades de canto }\end{array}$ & $02 \mathrm{FO}$ \\
\hline \multirow{2}{*}{ b. Trabalho/Estudo } & \begin{tabular}{l} 
Falta de ânimo e paciência \\
\cline { 2 - 4 }
\end{tabular} & Diminuição da capacidade & $04 \mathrm{FO}$ \\
\hline c. Atividades domésticas & \multirow{2}{*}{ 01UT } & $\begin{array}{l}\text { Incapacidade de realizar as } \\
\text { atividades domésticas }\end{array}$ & $02 \mathrm{FO}$ \\
\hline
\end{tabular}

Fonte: Dados da pesquisa de campo 
O impacto no "lazer" e "trabalho/estudo" apareceu como predominante, ocorrendo com 02UT cada um. Em seguida, apareceram "atividades domésticas", com apenas 01UT.

a. Lazer

Nesse eixo destacaram-se duas unidades temáticas: "dificuldade em participar de festas, eventos e passeios" e "limitação em participar de atividades de canto".

O lazer destaca-se como atividade muito afetada pela DTM. Os sujeitos relatam a perda da vontade em participar das reuniões familiares e sociais (09FO) e a necessidade de ficarem quietos para não agravarem a dor na face.

Di Fabio (1998 apud Lucena, 2004) comparou incapacidades e o estado de saúde associado com desordens temporomandibulares e outras desordens musculoesqueléticas, para avaliar qualidade de vida relacionada à saúde. O instrumento genérico de qualidade de vida relacionada à saúde - Estudo de Resultados Médicos (Medical Outcomes Study - MOS-17), foi usado para avaliar os aspectos físicos e mentais da incapacidade associada à DTM. Os resultados mostraram que os pacientes com DTM tiveram limitações na dimensão social e bem-estar emocional, semelhante aos com desordens cervicais. Essa comparação torna-se pertinente, uma vez que ambas as patologias apresentam características de cronicidade.

"A gente não sente vontade de passear, de fazer lazer. Dá vontade só da pessoa ficar assim [...] num canto, parada, quietinha [...] Eu saía, passeava, mas agora que eu mudei". (E6)

“Eu cantava na igreja e não canto mais. [...] Preciso estender muito a voz e eu não posso porque senão ele (o maxilar) estrala (estala). Aí eu tenho medo quando ele estrala, porque já aconteceu isso [...] É tão ruim. Eu gosto tanto [...] É muito ruim, é horrível. Desde pequenininha eu cantava na igreja, aí no ano passado eu tava fazendo parte do coral da igreja. Eu tive que sair porque na hora do ensaio eu fui dar um agudo e não aguentei. Aí ele (o maxilar) desceu". (E5)

\section{b. Trabalho/Estudo}

Macfarlane et al. (2002 apud Oliveira, 2003), apesar de terem estudado pacientes com dores orofaciais de diferentes origens, demonstraram, em 2.504 pacientes, um importante impacto da dor orofacial no trabalho, com $17 \%$ de relatos de perda de dias de trabalho e incapacidade de desenvolverem suas atividades como antes da dor.

Segundo dados da Sociedade Brasileira para Estudos da Dor (SBED, 2007)

A dor afeta pelo menos $30 \%$ dos indivíduos durante algum momento da sua vida e, em 10 a 40\% deles, tem duração superior a um dia. Constitui a causa principal de sofrimento, incapacitação para o trabalho e ocasiona graves consequências psicossociais e econômicas. Muitos dias de trabalho podem ser perdidos por aproximadamente $40 \%$ dos indivíduos. Não existem dados estatísticos oficiais sobre a dor no Brasil, mas a sua ocorrência tem aumentado substancialmente nos últimos anos.

Nesta investigação, no eixo temático "trabalho / estudo", ocorreram duas unidades temáticas: a "falta de ânimo e paciência", com 04FO, e "diminuição da capacidade", com 06FO.

“Tem dia que eu já passei sem ir (para o colégio) uma semana, quase. Porque a cabeça / dói a cabeça. Aí, dói o ouvido. Sai doendo é tudo. Se for doendo eu não estudo [...] Não dá vontade de assistir televisão, não dá vontade de fazer nada. [...] Ficar quieto". (E9)

"É, eu trabalho o dia todo falando, e eu tô sentindo dificuldade pra falar. É, tá atrapalhando". (E18) 


\section{c. Atividades domésticas}

No eixo temático referente ao impacto na realização das atividades domésticas, ocorreu apenas uma unidade temática: "incapacidade de realizar as atividades", com 02FO.

Formas mais sutis de alterações na disposição para atividades domésticas, relatadas por BiasottoGonzalez et al. (2009), ao estudarem a qualidade de vida em portadores de DTM, são demonstradas ao se comprovar a influência da dor no domínio da vitalidade.

Oliveira et al. (2003) também apontam prejuízos nas atividades domiciliares de pacientes com DTM, na proporção de $54,55 \%$.

Pensando nessas atividades domésticas, são relatadas limitações totais ou parciais.

“Impede. Que você querer fazer aquilo com dor / que pode tomar qualquer remédio pra ver se alivia aquela dor. Agora, se fosse direto eu acho que eu não agüentava não. Que tem gente aqui (pacientes na sala de espera), que diz que é direto. Eu não vou dizer que é direto, que não é. De repente ela chega assim [...] de repente". (E3)

\section{Impactos específicos em ser portador de DTM}

Consideraram-se dificuldades específicas aquelas que causam impactos diretamente às atividades relacionadas às funções orais e/ou da face.

“[..]/ pra comer / eu não mastigo chiclete, não chupo pirulito, eu não rôo osso eu não gosto de nada duro. Incomoda bastante. Pra bocejar dói muito, uma dor fina. É horrível. É muito ruim mesmo [...] agora mesmo tá doendo. Quando eu acordo pra escovar os dentes, dói. Quando eu vou falar [...] quando eu falo ou fico bocejando. Às vezes quando eu tô normal assim / fica latejando aqui ((indicação))". (E6)

Quadro 2. Impactos específicos em ser portador de DTM. Recife, 2010

\begin{tabular}{|c|c|c|c|}
\hline Eixos temáticos & $\begin{array}{l}\text { Número de Unidades } \\
\text { Temáticas (UT) por eixo } \\
\text { temático }\end{array}$ & Unidades temáticas & $\begin{array}{l}\text { Frequência de ocorrência } \\
\text { (FO) por unidade } \\
\text { temática }\end{array}$ \\
\hline \multirow[t]{5}{*}{ a. Mastigar } & \multirow[t]{5}{*}{ 05UT } & Movimentação da boca & 08FO \\
\hline & & Consistência dos alimentos & 07FO \\
\hline & & Modificação da dieta & 06FO \\
\hline & & Perda de apetite e peso & $02 \mathrm{FO}$ \\
\hline & & $\begin{array}{c}\text { Transtorno no convívio familiar } \\
\text { e/ou social }\end{array}$ & $02 \mathrm{FO}$ \\
\hline \multirow[t]{4}{*}{ b. Falar } & \multirow[t]{4}{*}{ 04UT } & Dor & 05FO \\
\hline & & Evitação de falar & $02 \mathrm{FO}$ \\
\hline & & Prejuízos profissionais & $02 \mathrm{FO}$ \\
\hline & & Adaptação para falar & 01FO \\
\hline
\end{tabular}


Quadro 2. Continuação

\begin{tabular}{|c|c|c|c|}
\hline \multirow{4}{*}{$\begin{array}{l}\text { c. Fazer higiene oral ou } \\
\text { da face }\end{array}$} & \multirow[t]{4}{*}{ 04UT } & Sofrimento com a escovação & 04FO \\
\hline & & Problemas em abrir a boca & 03FO \\
\hline & & Prejudica porque incomoda & 03FO \\
\hline & & Incômodo com o fio dental & 02FO \\
\hline \multirow[t]{3}{*}{ d. Bocejar } & \multirow[t]{3}{*}{ O3UT } & Sofrimento no bocejo & 07FO \\
\hline & & Evita bocejar & 06FO \\
\hline & & Não tem hábito de bocejar & 01FO \\
\hline \multirow{3}{*}{$\begin{array}{l}\text { e. Ficar com o rosto } \\
\text { normal sem aparência } \\
\text { de dor ou triste }\end{array}$} & \multirow[t]{3}{*}{ O3UT } & $\begin{array}{l}\text { Não consegue, fica triste, } \\
\text { amuado ou sem prazer }\end{array}$ & 06FO \\
\hline & & $\begin{array}{c}\text { Procura disfarçar a aparência } \\
\text { ou não valorizar }\end{array}$ & $02 \mathrm{FO}$ \\
\hline & & $\begin{array}{l}\text { Difícil não ficar com aparência } \\
\text { de dor ou/ e triste }\end{array}$ & 01FO \\
\hline \multirow[t]{2}{*}{ f. Sorrir e gargalhar } & \multirow[t]{2}{*}{$02 U T$} & Medo ou incômodo & 06FO \\
\hline & & Impedimento & 05FO \\
\hline \multirow[t]{2}{*}{ g. Atividades sexuais } & \multirow[t]{2}{*}{ 02UT } & Dor e incômodo no beijo & 03FO \\
\hline & & Incômodo na atividade sexual & 03FO \\
\hline \multirow[t]{2}{*}{ h. Fazer exercícios } & \multirow[t]{2}{*}{ 02UT } & $\begin{array}{l}\text { Mal-estar na realização de } \\
\text { atividades físicas }\end{array}$ & 03FO \\
\hline & & Redução das atividades físicas & 02FO \\
\hline
\end{tabular}

Fonte: Dados da pesquisa de campo

Nos enunciados dos entrevistados sobre os impactos específicos em ser portador de DTM foram encontrados, como eixos temáticos mais frequentes, os seguintes temas: Mastigar (05UT); Falar (04UT); Fazer higiene oral e da face (04UT); Bocejar (03UT); Ficar com o rosto normal sem aparência de dor ou triste (03UT); Sorrir e gargalhar (02UT); Atividade sexual (02UT) e Fazer exercícios físicos (02UT).

\section{a. Mastigação}

Mastigar é uma das funções orais que demanda grande atividade da articulação temporomandibular (ATM) e dos músculos relacionados, estruturas que, geralmente, estão comprometidas na DTM.

Os achados de Murray et al. (2001 apud Oliveira, 2003) mostraram um significante impacto na qualidade de vida dos portadores de DTM quando comparados à população sem queixa de dor. Os 
relatos de problemas funcionais, como dificuldade para mastigar determinados alimentos, foram quatro vezes maiores para os pacientes estudados, e os relatos de depressão nove vezes maior.

No eixo temático da "mastigação" apareceu, como mais frequente, limitação na "movimentação da boca", com 08FO; seguido das queixas quanto à "consistência dos alimentos", com 07FO; "modificação da dieta", com 06FO; "perda de peso", com 02FO, e "transtorno no convívio familiar e/ou social", também com 02FO.

“Às vezes é só no movimento que eu vou abrir a boca, aí já dói. Às vezes eu tenho que segurar aqui ((indicação)) um pouquinho, botar a mão, porque pra fazer os movimentos / porque ela dói. Agora mesmo tá doendo. Mas, é uma dorzinha que tá incomodando, uma dorzinha fina lá dentro. Mas se eu for fazer um movimento mais forte, aí ela dói mais". (E4)

“Dói quando mastiga. Ela dá uma dor fina e começa a estalar [...] O duro é mais dificultoso. [...] Aqueles coquinho de macaíba... Tinha tempo que eu comia aquilo demais. Agora eu não posso. (E2)

"Assim [...] eu gosto muito de ossinho, não posso mais. Carne dura, eu não posso, assim, pegar e puxar. Dói. Tem que ser assim cortadinha (a carne). Tem que ser o mínimo de mastigado possível /.../ teve um tempo assim, que quando tava doendo muito, muito, muito, aí eu comecei evitar (de comer alimentos duros). Trocando o almoço por um copo de suco ou por uma vitamina. Aí foi quando eu perdi três ou quatro quilos por causa disso. Eu era bem cheinha". (E5)

"Fico que eu não posso nem mastigar nada e sem abrir a boca. /.../ Até 3Kg eu perdi porque não consigo comer de jeito nenhum. Porque quando eu tô com essa dor, eu não consigo comer nada". (E3)

"Assim [...] nos primeiros tempos quando eu almoçava, eu não almoçava na mesa porque estralava ((estalos/clics provenientes da ATM)). Toda vez que eu comia / muito alto. Incomodava quem tava na mesa, tá, tá, tá. Minha mãe botava o almoço, eu ia pro quarto". (E5)

Embora Carrascosa, Campos e Faria (2008) ressaltem uma carência de estudos que demonstrem evidências que as DTM causem algum impacto relacionado à alimentação e este sobre a qualidade de vida, o presente estudo pôde constatar essa ocorrência.

Nesse sentido, as narrativas apontam que a privação dos alimentos preferidos, a lentidão para alimentar-se, a inapetência, a perda de peso e a dor, são algumas das características do processo de alimentação dos sujeitos estudados, tendo em vista que a alimentação é uma função básica necessária à sobrevivência, que, além de fins nutricionais, possui um caráter social e de satisfação.

\section{b. Falar}

São muito controvertidos os estudos fonoaudiológicos que correlacionam a existência de queixas na fala e DTM. Isso se deve, provavelmente, à ausência dessas questões nos protocolos de anamnese de DTM, para que os sujeitos pudessem referi-las.

Alguns dos estudos que relatam a presença dessa relação são os trabalhos de Felício (1994), Anelli (1997) e Bianchini (1998). Contudo, Taucci (2006), aprofundando o estudo nessa área, concluiu que as queixas de fala mais frequentes, referidas pelos indivíduos com DTM, são, em ordem decrescente: ruídos na articulação, cansaço após longos períodos de fala, limitações no movimento mandibular na presença de dor e desvios na mandíbula, deslocamentos, travamento e rouquidão.

Neste estudo, ocorreu, com maior frequência, a dor ao falar, com 05FO; seguida de "evitação de falar" e "prejuízos profissionais", ambas com 02FO; e, por fim, "adaptação para falar", com 01FO. 
“Conversar também. Eu evito conversar. Porque se abrir a boca [...]. Qualquer movimento, dói [...] É uma tortura". (E3)

“Às vezes, quando converso. [...] Agora mesmo tá doendo. (E5)

"Como eu lhe disse, é péssimo. Não é? Porque tem várias coisas que eu gostaria de fazer e não posso fazer por causa da dor de cabeça que dá. [...] Agora mesmo eu tava conversando com a menina ((na sala de espera)) e deu a dor fina no maxilar". (E2)

“Eu trabalho falando. Não posso ficar assim. Me incomoda muito. [..]/ Não posso abrir muito a boca. Agora, (falar) mais alto, (e) mais grosso, eu não posso. [...] Porque eu trabalho com telemarketing, e não pode ter dificuldade pra quem está ouvindo". (E17)

\footnotetext{
"Isso incomoda no dia-a-dia. Agora, assim [...] em trabalho /questão de trabalho. Porque eu já fiz seleções de empregos pra casos de tele-atendimento. He::: Call Center. E justamente quando eu passo pela tal da fonoaudióloga [...]. Aí ela mede, ela aperta, ela nota que tem dor, ela me reprova. [..]/ Aí quando chega à última fase, que é a fase da fonoaudióloga, aí estralou (estalou). Estralou três vezes. Eu não disse a ela que eu estava sentindo dor, mas ela notou. E::: viu pelo estralo. Pegou e me reprovou. Duas vezes. [...] Eu fiz três seleções diferentes e todas as três eu fui reprovada. Por esse motivo. Sempre, na parte da fonoaudióloga, ela me reprova". (E11)
}

\section{c. Fazer higiene oral e da face}

Em se tratando das limitações relacionadas com a higiene oral e da face, surgiram quatro unidades temáticas relevantes. A primeira, "sofrimento com a escovação" (04FO); em seguida, "problemas em abrir a boca" e "prejudica porque incomoda" (ambas com 03FO); e, por fim, "incômodo com o fio dental" (02FO).

Inicialmente, é observado, nas unidades temáticas, que a escovação representa uma dificuldade importante. Esse sofrimento se caracteriza, sobretudo, pela dor na realização da higiene. Essas dores não caracterizam exatamente um quadro de DTM, ocorrendo, mais frequentemente, em decorrência de patologias do próprio dente.

Esses dados, demonstrados nos enunciados a seguir, corroboram com os achados de Oliveira et al. (2003), que estudaram a influência da DTM no cotidiano.

\footnotetext{
“Rapaz [...] (escovar) os dentes tem hora que incomoda. (lavar) A face não. Mas os dentes
} $[\ldots] " .(E 18)$

"[...] eu sinto muita dificuldade, porque quando eu abro, ele desloca. Com a deslocação vêm os estralos (clics). O cansaço vem também". (E17)

“Às vezes incomoda um pouco, queima, mas tem que fazer também, né?'. (E15)

"[...] com fio dental, machuca!". (E5)

\section{d. Bocejar}

Chaves, Oliveira e Grossi (2008), estudando os principais instrumentos para avaliação da DTM, destacam o ato de bocejar como um dos itens que merecem ser investigados, uma vez que está presente na maioria deles.

Na presente pesquisa, bocejar aparece em quarto lugar na variação de temas (3UT) relacionados com os impactos específicos da DTM. Entre as unidades temáticas, surgem: "sofrimento no bocejo" (07FO); "evita bocejar" (06FO); e, por fim, "não tem hábito de bocejar" (01FO). 
"Oh:.:, demais, demais [...] Pra bocejar dói muito. Uma dor fina. É horrível!". (E5)

"Sim, eu fiquei com trauma de abrir a boca. Tem que abrir só um pouquinho, porque parece que vai descolar". (E15)

“He::: Essa questão aí não impede porque não sei se é porque eu num tenho esse hábito não de [...] de bocejar. Eu não sei o porquê". (E8)

e. Ficar com o rosto normal, sem aparência de dor ou de triste

A face, além da voz, também é um importante instrumento de comunicação. As expressões faciais, por serem um relevante meio de expressão não verbal, não conseguem esconder a experiência de sofrimento físico e psíquico com a dor. Nos vários recortes, foram encontradas, como unidades temáticas mais prevalentes, as seguintes: não consegue, fica triste, amuado e sem prazer (06FO); procura disfarçar ou não valorizar (02FO), e difícil não ficar (01FO).

O estudo das dores crônicas e suas formas de manifestação, como lembra Oliveira (2000), não pode ficar restrito aos aspectos puramente biológicos. Dessa forma, os enunciados que se seguem ressaltam que a dor, quando se caracteriza como um problema recorrente na vida do sujeito, é sempre "comunicada" em determinadas expressões faciais.

"A cara de triste eu fico. Porque eu sinto um pouco. Porque quando a gente tá com problema e não resolve (a dor que não melhora)/.../ Mas aí me incomoda, aí eu fico triste". (E14)

“Impede sim. Porque quando você está com a dor, você não fica tão relaxado, você fica contraído. Você não se distrai com outra coisa, porque tem dor. E ela (a dor) acaba lhe tirando prazer de certas coisas". (E17)

"Ah::: meu Deus! A gente tenta disfarçar, né doutora? Mas dói. Só Deus é que sabe. E como diz o ditado: "que só quem tá calçando o sapato é que sabe onde tá apertado", né? Imagine a gente que convive com essa dor. Às vezes a gente tenta disfarçar, mas não dá o que saber a todo mundo, o que a gente tá sentindo". (E6)

"Aí é difícil né?". (E8)

\section{f. Sorrir e gargalhar}

As atividades de sorrir e gargalhar necessitam da atividade da musculatura orofacial e são as mais simples expressões de felicidade e satisfação. Contudo, necessitam da ativação da mímica facial e, sobretudo, da abertura da cavidade oral (Douglas, 2002). Nesse sentido, os sujeitos portadores de DTM, embora não gozem de muita satisfação, pois sofrem de dor crônica, quando a possuem, não podem demonstrá-la, já que essa atividade lhes causa agravo do processo doloroso, como mostram as narrativas desta pesquisa.

Entre as unidades temáticas presentes nos enunciados, surgem: o "incômodo e medo ao sorrir" (06FO) e "impedimento" (05FO).

“[...] tinha época que até eu ria mais. Aí, agora eu fico até com medo [...]. Porque eu gosto muito de rir, aí, eu fico até com medo". (E16)

"Sorrir incomoda. E quando eu abro o sorriso no maxilar, a parte inferior, ele (o maxilar) muda (desvia). Desvia para o lado. [...] É, pro lado esquerdo. Então, eu tenho que controlar o sorriso". (E17)

"Quando tá atacada (na crise), eu não posso rir". (E6) 


\section{g. Atividade sexual}

A pergunta da entrevista que originou esse tema intencionava indagar sobre a atividade sexual. Entretanto, as respostas dos impedimentos envolveram unidades temáticas específicas, como "beijo" (03FO), e mais amplas, como "incômodo na atividade sexual" (03FO)

Carvalho (1999), em seu estudo multidisciplinar sobre a dor crônica, afirma que este sofrimento provoca um grande impacto sobre o estilo de vida do indivíduo, produz alterações vegetativas, incluindo insônia, falta de apetite e desejo sexual.

Sobre este item, os sujeitos entrevistados afirmam:

"Atrapalhou no início. Quando meu esposo vinha me beijar. Às vezes ele vinha assim [...] de supetão. Aí doía". (E6)

"Quando eu tô com qualquer dor, você não consegue fazer [...]". (E3)

\section{h. Exercícios físicos}

Nos enunciados dos entrevistados, surgem duas unidades temáticas em relação a fazer exercícios físicos. Uma relacionada ao "mal-estar" (03FO) e outra com a necessidade de "redução" (02FO) total ou parcial.

Os dados acima podem ser justificados a partir da constatação de que a DTM pode ocasionar sintomas físicos, como: dores de cabeça, problemas no aparelho locomotor, dores musculares, câimbras, limitações de algum movimento do corpo, dores ósseas, formigamentos e diminuição da sensibilidade, como demonstra o estudo de Bove, Guimarães e Smith (2005).

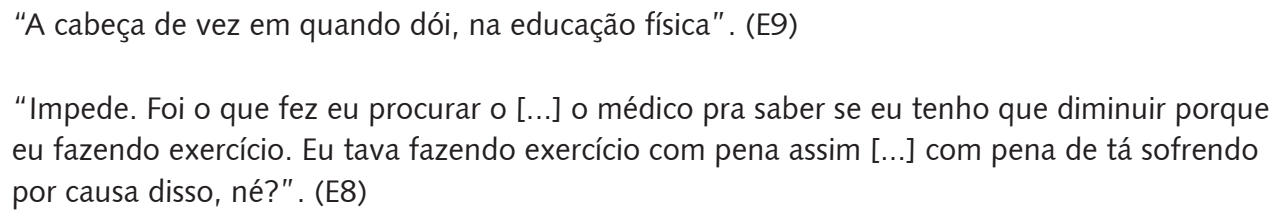

Parece uma ironia sentir dor para falar da dor. Apesar de a DTM apresentar características semelhantes a todas as outras dores crônicas, como já foi comentado anteriormente, existe um caráter a ser considerado - a localização dessa dor. A face, região mais referida pelos sujeitos com DTM, e mais especificamente a boca, é também a região por onde se expressa a dor. Essa infeliz coincidência termina por provocar transtornos específicos acrescidos ao desprazer comum à dor.

Outros impactos são igualmente relevantes e até aparecem com valores absolutos mais evidentes neste estudo. Contudo, é dado um destaque ao tema "impactos na fala", pois se considera que eles causem um comprometimento mais relevante na comunicação de uma forma geral. $\mathrm{O}$ ato da fala e, por conseguinte, o relato sofre prejuízos pela limitação objetiva da articulação da fala. A diminuição dos enunciados e a redução das explicações por causa da presença da dor podem provocar comprometimento na transmissão da informação dessa experiência.

\section{Considerações finais}

O presente estudo, que objetivou apreender o impacto da experiência de ser portador de DTM nas atividades sociais, de lazer e de familiares dos sujeitos, destacou, por meio da análise temática dos enunciados, que os impactos gerais da DTM na vida do sujeito são predominantemente no lazer e no trabalho. E, entre os impactos específicos, temos: mastigar, bocejar, fazer higiene oral, sorrir ou gargalhar e falar. 
A condição dolorosa, além das limitações orgânicas, provoca uma série de comprometimentos socioafetivos. Nesse sentido, a investigação desses impactos possibilita, ao profissional de saúde, assistir o sujeito de forma particular, compreendendo qual o impacto causado por aquela dor e por que isso é relevante para o sujeito, e, desse modo, obter um maior sucesso diagnóstico e tratamento. Trata-se de conhecer o paciente além de seus sintomas.

Esse conhecimento, por sua vez, necessita, entre outros fatores, de um processo comunicativo eficiente. É necessário que o conteúdo dos discursos seja compartilhado e atinja seu objetivo de constituição do produto de interação entre interlocutores.

Sendo assim, espera-se que estudos como estes, que se destinam a investigar os enunciados dos sujeitos com dor crônica, propiciem um melhor entendimento sobre a comunicação dos aspectos orgânicos e psicossociais da dor, mas, sobretudo, sirvam para implementação de programas de incentivo à interação profissional de saúde/paciente.

\section{Colaboradores}

Os autores trabalharam juntos em todas as etapas de produção do manuscrito.

\section{Referências}

ALVES, P.C.B.; RABELO, M.C.M. Significação e metáforas na experiência da enfermidade. In: RABELO, M.C.M.; ALVES, P.C.B.; SOUZA, I.M.A. (Orgs.). Experiência de doença e narrativas. Rio de Janeiro: Fiocruz, 1999. p.171-85.

ANELLI, W. Atuação fonoaudiológica na disfunção temporomandibular, In: LOPES FILHO, O.C. (Org.). Tratado de fonoaudiologia. São Paulo: Roca, 1997. cap.36. p.821-88.

BARDIN, L. Análise de conteúdo. Lisboa: Edições 70, 1995.

BIANCHINI, E.M.G. Disfunção da articulação temporomandibular: relações com a articulação da fala. 1998. Dissertação (Mestrado de Fonoaudiologia) - Pontifícia Universidade Católica de São Paulo, São Paulo. 1998.

BIASOTTO-GONZÁLEZ, D.A. et al. Qualidade de vida em portadores de disfunção temporomandibular- um estudo transversal. Rev. Inst. Cienc Saude, v.27, n.2, p.128-32, 2009.

BOEHS, A.E. A narrativa no mundo dos que cuidam e são cuidados. Rev. Latino-Am. Enferm., v.8, n.3, p.5-10, 2000.

BOVE, S.R.K.; GUIMARÃES, A.S.; SMITH, R.L. Caracterização dos pacientes de um ambulatório de disfunção temporomandibular e dor orofacial. Rev. Latino-Am. Enferm., v.13, n.5, p.686-91, 2005.

CARRASCOSA, A.C.; CAMPOS, J.A.D.B.; FARIA, J.B. Disfunções temporomandibulares, alimentação e nutrição: revisão da literatura. Alim. Nutr., v.19, n.4, p.499-504, 2008.

CARVALHO, M.M.M.J. (Org.). Dor : um estudo multidisciplinar. 2.ed. São Paulo: Summus, 1999.

CHAVES, T.C.; OLIVEIRA, A.S.; GROSSI, D.B. Principais instrumentos para avaliação da disfunção temporomandibular, parte I: índices e questionários; uma contribuição para a prática clínica e de pesquisa. Fisioter. Pesqui., v.15, n.1, p.92-100, 2008.

DICIONÁRIO Houaiss da Língua Portuguesa. Disponível em: <http://houaiss.uol.com.br/ busca.jhtm?verbete $=$ anamnese\&stype $=k>$. Acesso em: 17 jan. 2008.

DOUGLAS, C.R. Tratado de Fisiologia aplicada à Fonoaudiologia. São Paulo: Robe Editorial, 2002. 
FELÍCIO, C.M. Fonoaudiologia nas desordens temporomandibulares: uma ação educativa-terapêutica. São Paulo: Pancast, 1994.

FONSECA, D.M. et al. Diagnóstico pela anamnese da disfunção craniomandibular. Rev. Gaucha Odontol., v.42, n.1, p.23-8, 1994.

FRANCO, M.L.P.B. Análise de conteúdo. Brasília: Plano Editora, 2003.

GARCIA, A.R. et al. Joint vibration analysis in patients with articular inflammation. Cranio, v.18, n.4, p.272-9, 2000.

GOOD, B.J. Medicine, rationality and experience: an anthropological perspective. Cambridge: University Press, 1994.

GRZESIAK, R.C. Psychologic considerations in temporomandibular dysfunction. Dental Clin. North Am., v.35, n.1, p.209-25, 1991.

HELMAN, C.G. Cultura, saúde \& doença. 4.ed. Porto Alegre: Artmed, 2003.

IRIART, J.A.B. Concepções e representações da saúde e da doença: contribuições da antropologia da saúde para a saúde coletiva. Salvador: UFBA/ISC, 2003. (Texto didático).

JOVCHELOVITCH, S.; BAUER, M.W. Entrevista narrativa. In: BAUER, M.; GASKELL, G. (Orgs.). Pesquisa qualitativa com texto, imagem e som: um manual prático. Petrópolis: Vozes, 2002. p.90-113.

KLEINMANN, A. Patients and Healers in the context of the culture: an exploration of the borderland betwen anthropology, medicine and psychiatry. Califórnia: Regents, 1980

KOSMINSKY, M. et al. Adaptação cultural do questionário research diagnostic criteria for temporomandibular disorders: axis II para o Português. J. Bras. Clín. Odontol. Integr., v.8, n.43, p.51-61, 2004.

LANGDON, E.J.M. A negociação do oculto: xamanismo, família e medicina entre os siona no contexto pluri-étnico. Santa Catarina: UFSC, 1994. Trabalho apresentado para Concurso de Professor Titular, Universidade Federal de Santa Catarina. 1994.

LIMA, M.C.; RIVERA, F.J.U. Communicative action, networks of conversation and coordination in healthcare services: a theoretical and methodological perspective. Interface - Comunic., Saude, Educ., v.13, n.31, p.329-42, 2009.

LIRA, G.V.; CATRIB, A.M.F.; NATIONS, M.K. A narrativa da pesquisa social em saúde: perspectiva e método. Rev. Bras. Prom. Saude, v.16, n.1/2, p.59-66, 2003.

LUCENA, L.B.S. O impacto da disfunção temporomandibular na qualidade de vida relacionada à saúde bucal. 2004. Tese (Doutorado) - Universidade Federal da Paraíba, Universidade Federal da Bahia, João Pessoa. 2004.

MINAYO, M.C.S. O desafio do conhecimento: pesquisa qualitativa em saúde. São Paulo: Hucitec, 2006.

MURRAY, H. et al. Pain and the quality of life in patients referred to a craniofacial unit. J. Orofac. Pain, v.10, n.4, p.316-23, 1996.

OLIVEIRA, A.S. et al. Pain impact on life of patients with temporomandibular disorder. J. Appl. Oral Sci., v.11, n.2, p.138-43, 2003.

OLIVEIRA, J.T. Aspectos comportamentais das síndromes de dor crônica. Arq. Neuropsiquiatr., v.58, n.2-A, p.360-5, 2000.

PRETI, D. (Org.). Fala e escrita em questão: projetos paralelos NURC/SP. São Paulo: Humanistas/FFLCH/USP, 2000.

SANTOS, J.B. Ouvir o paciente: a anamnese no diagnóstico clínico. Brasília Med., v. 36, n.3/4, p.90-5, 1999.

SILVA, D.G.V.; TRENTINI, M. Narrativas como técnica de pesquisa em enfermagem.

Rev. Latino-Am. Enferm., v.10, n.3, p.423-32, 2002. 
SIQUEIRA, J.T.T. Dores mudas: as conseqüências das dores orofaciais na saúde. Curitiba: Editora Maio, 2004.

SIQUEIRA, J.T.T.; TEIXEIRA, M.J. Dor orofocial: diagnóstico, terapêutica e qualidade de vida. Curitiba: Editora Maio, 2001.

SLEVIN, M.L. et al. Who should measure quality of life, the doctor or the patient? Br. J. Cancer, v. 57, n.1, p.109-112, 1988.

STUDART, L. A linguagem da dor: um estudo dos enunciados de sujeitos portadores de disfunção temporomandibular. 2008. Dissertação (Mestrado) - Universidade Católica de Pernambuco, Recife. 2008.

SOCIEDADE BRASILEIRA PARA ESTUDOS DA DOR. Dor: impactos conseqüentes da dor. Rio de Janeiro: Sociedade Brasileira Para Estudos da Dor. Disponível em: <http:// www. dor.org.br/dor_classificacao.asp>. Acesso em: 20 nov. 2007.

TAUCCI, R.A. Verificação da interferência das disfunções temporomandibulares na articulação da fala: queixas e caracterização dos movimentos mandibulares. 2006. Dissertação (Mestrado) - Universidade Veiga de Almeida, Rio de Janeiro. 2006.

TRASK, R. L. Dicionário de linguagem e lingüística. São Paulo: Contexto, 2004.

TURNER, V. Social dramas and stories about them. In: MITCHEL, W.J.T. (Org.). On narrative. Chicago: The University of Chicago Press, 1984. p.137-64.

WHITE, $\mathrm{H}$. The value of narrativity in the representation of reality. On narrative, v.7, n. 1, p. 5-27, 1981.

ZARB, G. A. et al. Disfunções da articulação temporomandibular e dos músculos da mastigação. 2.ed. São Paulo: Santos, 2000.

STUDART, L.; ACIOLI, M.D. Comunicación de dolor: un estudio sobre las narraciones acerca de los impactos de los trastornos temporomandibulares. Interface - Comunic., Saude, Educ., v.15, n.37, p.487-503, abr./jun. 2011.

Interés por la realización de investigaciones sobre el dolor y la calidad de vida han sido frecuentes en la salud. La mayoría tiene por objeto el análisis cuantitativo. En consecuencia, existe una demanda para desarrollar métodos de investigación, utilizando instrumentos que focalicen la perspectiva del sujeto y que permitan una mejor comprensión de la experiencia del sufrimiento. Esa investigación tuvo como objetivo estudiar las narraciones de los sujetos con trastorno temporomandibular relacionadas con el impacto del dolor en las actividades sociales, de tiempo libre y en la familia. Para la constitución del corpus se utilizaron las entrevistas semi-estructuradas, grabadas y transcritas. La discusión de los resultados se basó en análisis de contenido. Los resultados indicaron que el impacto general de la pena de trastorno temporomandibular en la vida del sujeto está en su mayoría en el ocio y el trabajo. Impactos específicos incluyen masticar, bostezar, hacer la higiene oral, sonreír y hablar.

Palabras clave: Comunicación. Dolor orofacial. Narrativas. Calidad de vida. 
